\title{
Unmet need in severe, uncontrolled asthma: can anti-TSLP therapy with tezepelumab provide a valuable new treatment option?
}

\author{
Andrew Menzies-Gow ${ }^{1 *}$, Michael E. Wechsler ${ }^{2}$ and Chris E. Brightling ${ }^{3}$
}

\begin{abstract}
Despite treatment with standard-of-care medications, including currently available biologic therapies, many patients with severe asthma have uncontrolled disease, which is associated with a high risk of hospitalization and high healthcare costs. Biologic therapies approved for severe asthma have indications limited to patients with either eosinophilic or allergic phenotypes; there are currently no approved biologics for patients with eosinophil-low asthma. Furthermore, existing biologic treatments decrease exacerbation rates by approximately $50 \%$ only, which may be because they target individual, downstream elements of the asthma inflammatory response, leaving other components untreated. Targeting an upstream mediator of the inflammatory response may have a broader effect on airway inflammation and provide more effective asthma control. One such potential target is thymic stromal lymphopoietin (TSLP), an epithelial-derived cytokine released in response to multiple triggers associated with asthma exacerbations, such as viruses, allergens, pollutants and other airborne irritants. Mechanistic studies indicate that TSLP drives eosinophilic (including allergic) inflammation, neutrophilic inflammation and structural changes to the airway in asthma through actions on a wide variety of adaptive and innate immune cells and structural cells. Tezepelumab is a first-in-class human monoclonal antibody that blocks the activity of TSLP. In the phase $2 \mathrm{~b}$ PATHWAY study (NCT02054130), tezepelumab reduced asthma exacerbations by up to $71 \%$ compared with placebo in patients with severe, uncontrolled asthma across the spectrum of inflammatory phenotypes, and improved lung function and asthma control. Phase 3 trials of tezepelumab are underway. NAVIGATOR (NCT03347279), a pivotal exacerbation study, aims to assess the potential efficacy of tezepelumab further in patients with a broad range of severe asthma phenotypes, including those with low blood eosinophil counts. SOURCE (NCT03406078) aims to evaluate the oral corticosteroid-sparing potential of tezepelumab. DESTINATION (NCT03706079) is a long-term extension study. In addition, an ongoing phase 2 bronchoscopy study, CASCADE (NCT03688074), aims to evaluate the effect of tezepelumab on airway inflammation and airway remodelling in patients across the spectrum of type 2 airway inflammation. Here, we summarize the unmet therapeutic need in severe asthma and the current treatment landscape, discuss the rationale for targeting TSLP in severe asthma therapy and describe the current development status of tezepelumab.
\end{abstract}

Keyword: Asthma, Biologics, Burden of illness, Phenotype, Tezepelumab, Thymic stromal lymphopoietin

\footnotetext{
* Correspondence: A.Menzies-Gow@rbht.nhs.uk

${ }^{1}$ Royal Brompton Hospital, Sydney Street, London SW3 6NP, UK

Full list of author information is available at the end of the article
}

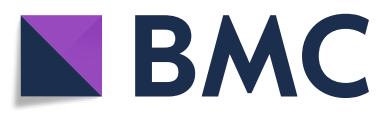

(c) The Author(s). 2020 Open Access This article is licensed under a Creative Commons Attribution 4.0 International License, which permits use, sharing, adaptation, distribution and reproduction in any medium or format, as long as you give appropriate credit to the original author(s) and the source, provide a link to the Creative Commons licence, and indicate if changes were made. The images or other third party material in this article are included in the article's Creative Commons licence, unless indicated otherwise in a credit line to the material. If material is not included in the article's Creative Commons licence and your intended use is not permitted by statutory regulation or exceeds the permitted use, you will need to obtain permission directly from the copyright holder. To view a copy of this licence, visit http://creativecommons.org/licenses/by/4.0/. The Creative Commons Public Domain Dedication waiver (http://creativecommons.org/publicdomain/zero/1.0/) applies to the data made available in this article, unless otherwise stated in a credit line to the data. 


\section{Background}

Asthma is a highly prevalent inflammatory disease of the airways, with current estimates putting the number of individuals with the condition at 339 million worldwide [1]. While the majority of these individuals have mild disease, approximately $5-10 \%$ have severe asthma [2, 3]. Many patients with severe asthma have disease that remains uncontrolled despite standard-of-care therapy [2, 4], which severely impacts their health-related quality of life (HRQoL) owing to persistent symptoms and frequent and life-threatening exacerbations $[5,6]$. Patients with severe asthma have a high rate of healthcare resource use, accounting for twice as many asthma-related hospitalizations as those with non-severe disease [7], and incur approximately two-threefold higher asthma-related healthcare and medication costs [7, 8]. Comorbidities of severe asthma are common and include chronic rhinosinusitis, nasal polyposis, allergic rhinitis and gastroesophageal reflux disease [9]. Furthermore, $20-60 \%$ of patients with severe or uncontrolled asthma may receive long-term oral corticosteroid (OCS) therapy [10], which is associated with a range of side effects including infections and cardiovascular, metabolic, psychiatric, ocular, gastrointestinal and bone-related complications [11].

The inflammation associated with asthma is heterogeneous, with considerable variation in the profiles of upregulated immune cells and biomarkers. From these profiles, several inflammatory phenotypes of asthma can be designated. The most common phenotypes involve eosinophilic (including allergic) type 2 (T2) inflammation. Eosinophilic phenotypes are characterized by elevated blood eosinophil counts, typically defined as at least 150 or 300 cells $/ \mu \mathrm{L}$, and/or elevated sputum eosinophil levels of at least 2-3\% [12]. In the case of allergic asthma, patients also exhibit a serum immunoglobulin (Ig) E level of at least $30 \mathrm{IU} / \mathrm{mL}$, in addition to sensitivity to a perennial aeroallergen and symptoms that are allergy-driven [13]. Fractional exhaled nitric oxide (FeNO) levels may also be elevated in patients with eosinophilic or allergic phenotypes, although there is not yet a consensus on the threshold that constitutes elevated FeNO. Other phenotypes are characterized by predominantly neutrophilic inflammation with normal eosinophil counts, elevated counts of eosinophils and neutrophils (mixed granulocytic inflammation), or by normal or low counts of neutrophils and eosinophils (paucigranulocytic inflammation) [12, 14, 15]. In relation to these phenotypes, it should be noted that corticosteroid therapy reduces eosinophil counts and may also increase neutrophil counts [16]; thus a patient's apparent phenotype may be a product of treatment choices rather than a true reflection of the underlying disease mechanisms. In addition to the heterogeneity of immune cells and biomarkers, there is variability among patients in other pathophysiological features of asthma, such as airway hyperresponsiveness and remodelling, which may be related to or separate from inflammatory events in the airways [17].

\section{Current treatment options for severe asthma}

The heterogeneity of severe asthma makes management of the disease highly challenging, and intensive treatment regimens involving multiple medications are required. Global Initiative for Asthma (GINA) guidelines (treatment steps 4 and 5) recommend a combination medium-tohigh-dose inhaled corticosteroid (ICS) and long-acting $\beta_{2}$ agonist (LABA) as maintenance therapy to prevent exacerbations and to control symptoms in these patients, with additional relief from a short-acting $\beta_{2}$ agonist as needed (or an ICS/LABA combination as both maintenance and reliever therapy, in the case of formoterol-containing combinations) [18]. Other controller medications recommended by GINA and European Respiratory Society/ American Thoracic Society guidelines for use as potential add-on therapies are inhaled tiotropium (a long-acting muscarinic antagonist; at GINA steps 4 or 5), leukotriene receptor antagonists (at step 4) and macrolides (at step 5) $[18,19]$. However, many patients have an insufficient response to these treatments and so are prescribed frequent bursts of OCS [10], although the side effect profile of OCS limits the dose and makes chronic administration nonideal. Furthermore, some patients have steroid-refractory disease. At GINA step 5, it is recommended that patients are assessed for eligibility for biologic therapies, which are indicated as additional controllers for specific phenotypes of severe asthma $[18,19]$. Eligibility for these therapies is partly determined by meeting specific inflammatory biomarker thresholds (and, by extension, phenotypes) for which efficacy of the particular biologic treatment was demonstrated in clinical trials.

Currently available biologics for severe asthma comprise anti-IgE (omalizumab), anti-IL-5 (mepolizumab, reslizumab), anti-IL-5 receptor $\alpha$ (benralizumab) and anti-IL-4 receptor $\alpha$ (dupilumab, which blocks the IL-4 and IL-13 pathways) monoclonal antibodies. These therapies are generally indicated for patients with eosinophilic or allergic asthma phenotypes; to date, there are no approved biologic treatments for patients with confirmed eosinophil-low asthma (in the absence of eosinophil-lowering systemic corticosteroid therapy). In the pivotal studies of the currently approved biologics, exacerbation rates were reduced by $48-$ $59 \%$ with the most efficacious dose regimen versus placebo [20-24]. Improvements in lung function and symptom scores were inconsistent, with only some individuals experiencing clinically significant improvements [25-28]. A possible explanation for this lack of complete efficacy may be that these biologics target individual, downstream elements of the asthma inflammatory response, leaving other components untreated. Targeting an upstream initiator and 
mediator of the inflammatory response may, therefore, have a broader effect on airway inflammation and provide more effective asthma control, including in patients with eosinophil-low phenotypes. One such potential target is thymic stromal lymphopoietin (TSLP).

\section{Thymic stromal lymphopoietin}

TSLP is a member of the class of cytokines known as the alarmins, which also includes IL-25 and IL-33. It is primarily expressed by the airway epithelium and released in response to environmental insults such as allergens, viruses, bacteria, pollutants and physical injury, instigating a range of downstream inflammatory processes $[29,30]$. There is strong evidence that TSLP dysregulation plays an important role in the pathophysiology of asthma.

TSLP expression is increased in the airways of patients with asthma compared with healthy individuals [31-34], correlating with disease severity and impairment of lung function [31, 33, 35, 36]. Furthermore, genome-wide association studies have identified associations between asthma risk and single-nucleotide polymorphisms in the TSLP gene [37-40].

Following its release from the epithelium, TSLP drives allergic and non-allergic eosinophilic inflammation, leading to various features of asthma pathophysiology [41]. TSLP activates dendritic cells in response to allergen exposure, inducing differentiation of naive $\mathrm{T}$ cells to $\mathrm{Th} 2$ cells, which produce IL-4, IL-5 and IL-13. This leads to IgE switching in B cells, degranulation of mast cells, airway eosinophilia, mucus hypersecretion from goblet cells and smooth muscle contraction resulting in airway hyperresponsiveness [42, 43]. Following exposure to viruses, bacteria, pollutants and other insults, TSLP (as well as IL33 and IL-25) activates group 2 innate lymphoid cells (ILC2s), which produce IL-5 and IL-13 [44]. In addition to its T2-related effects, there is growing evidence that TSLP plays a role in non-T2 processes involving both immune and structural cells. TSLP is thought to play a role in neutrophilic airway inflammation by activating dendritic cells to induce polarization of naïve $\mathrm{T}$ cells towards a Th17 phenotype, which subsequently release IL-17 $[45,46]$. TSLP also promotes airway remodelling by stimulating airway smooth muscle cell migration [47], facilitating cross-talk between mast cells and airway smooth muscle cells [48] and stimulating fibroblast cells to produce collagen $[49,50]$. The myriad effects of TSLP in asthma therefore make it an attractive therapeutic target.

\section{Tezepelumab}

Tezepelumab is a human monoclonal antibody (IgG2 $\lambda$ ) that selectively blocks TSLP from interacting with its heterodimeric receptor (Fig. 1) [51-53]. In a phase 1b, proofof-concept study in patients with mild allergic asthma (ClinicalTrials.gov identifier NCT01405963), tezepelumab attenuated asthmatic responses to allergen challenge and reduced biomarkers of inflammation compared with placebo [51]. In the tezepelumab group, blood eosinophil counts began to decline at 2 weeks post-dosing and reached normal levels by 4 weeks, while sputum eosinophils reached normal levels by 6 weeks (the first time point measured). FeNO levels improved significantly 1 week after the first dose. The phase 2b PATHWAY study, a multicentre, randomized, double-blind, placebocontrolled trial (NCT02054130) evaluated the efficacy and safety of tezepelumab as an add-on therapy for patients with severe, uncontrolled asthma, who were receiving medium-to-high-dose ICS and a LABA with or without OCS and additional asthma controllers [52]. Tezepelumab treatment was associated with significant reductions in annualized exacerbation rates of up to $71 \%$ versus placebo. Subgroup analyses showed that these reductions were significant irrespective of patient phenotype, as measured by baseline blood eosinophil counts $(<150$ cells $/ \mu \mathrm{L}, \geq 150$ cells $/ \mu \mathrm{L},<300$ cells $/ \mu \mathrm{L}$ or $\geq 300$ cells $/ \mu \mathrm{L}$ ), as well as by FeNO and IgE levels, suggesting that tezepelumab provided similar efficacy in patients across the spectrum of inflammatory phenotypes [54]. Compared with placebo, tezepelumab also reduced asthma-exacerbation-related hospitalizations and improved lung function, asthma control and patient HRQoL [52]. Further analyses of the PATHWAY data showed that tezepelumab reduced blood eosinophil counts, FeNO levels, serum IgE and cytokines including IL-5 and IL-13 $[52,55]$. Of the currently approved biologics, only anti-IgE has been shown to reduce FeNO levels, serum free IgE and blood or sputum eosinophil counts, although not to the same extent as anti-TSLP therapy [56]. The safety profile of tezepelumab in PATHWAY was acceptable, with a similar overall frequency of adverse events (including serious adverse events) in patients receiving tezepelumab and those receiving placebo; the most common adverse events were consistent with those expected in a patient population with severe asthma [52]. A low incidence of anti-drug antibodies was observed in patients treated with tezepelumab, without any apparent clinical impact. The observed efficacy of tezepelumab in a broad range of patients with severe asthma in PATHWAY led to it being designated a 'breakthrough therapy' by the US Food and Drug Administration in 2019 for patients with severe asthma without an eosinophilic phenotype, who are receiving ICS/LABA and additional asthma controllers with or without OCS [57].

Further trials of tezepelumab in patients with asthma are underway (Table 1). NAVIGATOR (NCT03347279) [58] is a pivotal phase 3 study assessing the potential efficacy of tezepelumab in adults and adolescents with severe, uncontrolled asthma spanning a broad range of phenotypes, aiming to build on the findings of PATHWAY. The 


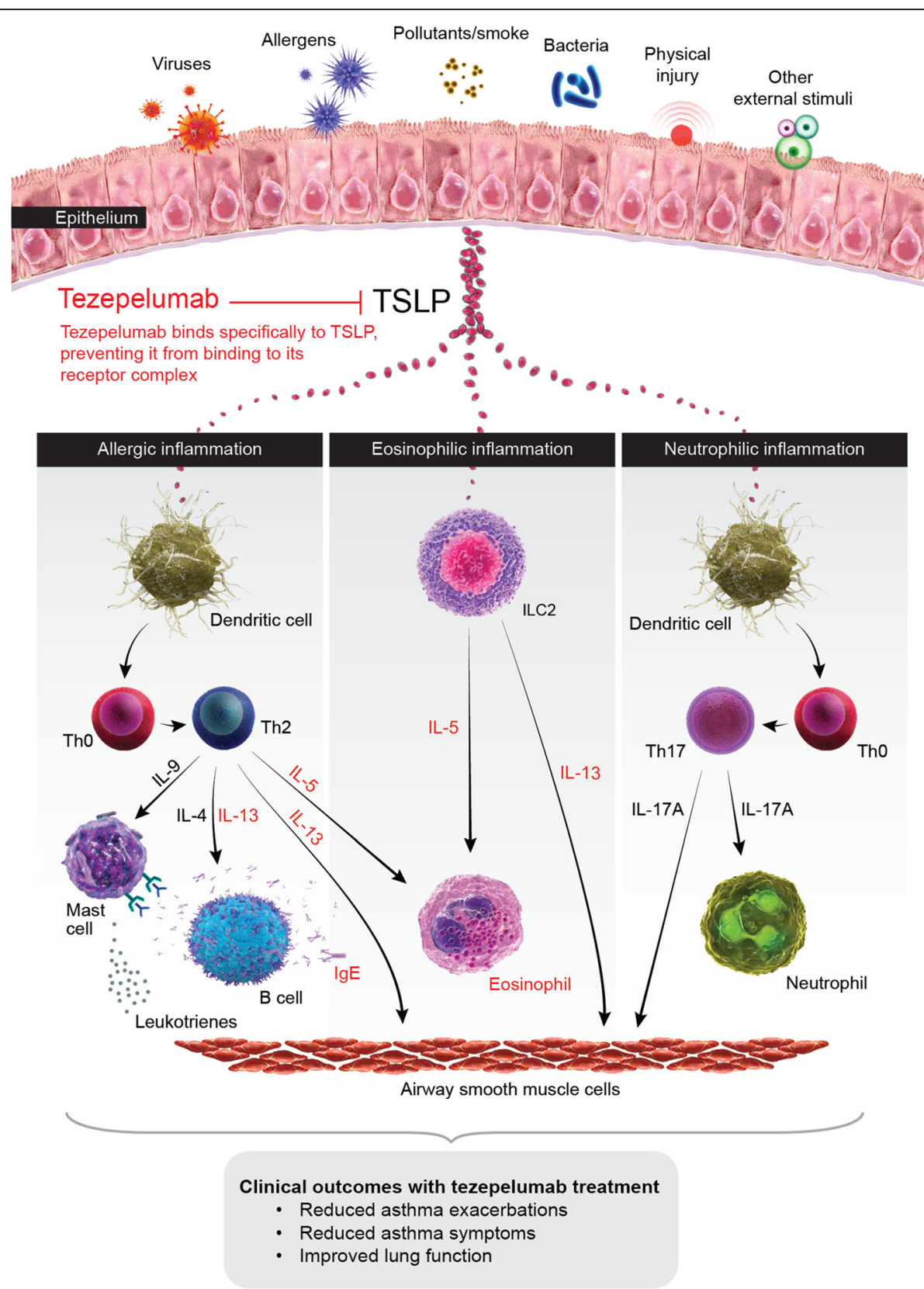

Fig. 1 Mechanism of action by which tezepelumab improves clinical outcomes in patients with severe asthma. TSLP is released from the airway epithelium in response to insults such as viruses, allergens and pollutants, triggering an inflammatory cascade. Overexpression of TSLP can result in pathologic inflammation that can lead to asthma exacerbations, symptoms, and physiological effects such as bronchoconstriction and airway hyperresponsiveness and remodelling. Tezepelumab specifically blocks TSLP from binding to its heterodimeric receptor, thereby inhibiting the production of various inflammatory cytokines and cell types. Treatment with tezepelumab has thus far been shown to reduce eosinophils, IgE, IL5, IL-13 and FeNO. FeNO, fractional exhaled nitric oxide; IgE, immunoglobulin E; IL, interleukin; ILC2, type 2 innate lymphoid cell; Th, T-helper; TSLP, thymic stromal lymphopoietin

recruited participants comprise roughly equal proportions of patients with baseline blood eosinophil counts of less than 300 cells $/ \mu \mathrm{L}$ and at least 300 cells $/ \mu \mathrm{L}$; approximately $25 \%$ of patients have an eosinophil count of less than 150 cells $/ \mu \mathrm{L}$ or of greater than 450 cells $/ \mu \mathrm{L}$. The primary efficacy endpoint is the annualized asthma exacerbation rate during the 52-week treatment period in the overall patient population, and this will also be assessed separately in patients with baseline blood eosinophil counts below 300 cells $/ \mu \mathrm{L}$. Key secondary endpoints of NAVIGATOR assess lung function, asthma control and HRQoL. SOURCE (NCT03406078) [59] is a phase 3 study that 
Table 1 Ongoing studies of tezepelumab in patients with asthma and healthy volunteers

\begin{tabular}{|c|c|c|c|c|}
\hline $\begin{array}{l}\text { ClinicalTrials.gov } \\
\text { identifier }\end{array}$ & $\begin{array}{l}\text { Estimated start and } \\
\text { completion dates }\end{array}$ & Patient population & Phase & Primary outcome \\
\hline $\begin{array}{l}\text { NCT02698501 } \\
\text { (UPSTREAM) }\end{array}$ & 2016-2019 & 40 adults with asthma requiring ICS ( \pm LABA) & 2 & Mannitol PD 15 \\
\hline $\begin{array}{l}\text { NCT03989544 } \\
\text { (PATH-BRIDGE) }\end{array}$ & 2019-2019 & 315 healthy adults & 1 & $\begin{array}{l}\text { Pharmacokinetics of SC administration via } \\
\text { accessorized pre-filled syringe or autoinjec } \\
\text { tor compared with vial and syringe }\end{array}$ \\
\hline $\begin{array}{l}\text { NCT03968978 } \\
\text { (PATH-HOME) }\end{array}$ & 2019-2020 & $\begin{array}{l}216 \text { adults and adolescents with severe } \\
\text { asthma }\end{array}$ & 3 & $\begin{array}{l}\text { Successful SC administration via } \\
\text { accessorized pre-filled syringe or autoinjec } \\
\text { tor at home versus in the clinic }\end{array}$ \\
\hline $\begin{array}{l}\text { NCT03347279 } \\
\text { (NAVIGATOR) }\end{array}$ & 2019-2020 & $\begin{array}{l}1038 \text { adults and adolescents with severe, } \\
\text { uncontrolled asthma, taking medium- to } \\
\text { high-dose ICS and at least one additional } \\
\text { asthma controller with or without OCS }\end{array}$ & 3 & Annualized asthma exacerbation rate \\
\hline $\begin{array}{l}\text { NCT03406078 } \\
\text { (SOURCE) }\end{array}$ & $2018-2020$ & $\begin{array}{l}150 \text { adults with oral corticosteroid-dependent } \\
\text { asthma (Americas, Europe) }\end{array}$ & 3 & Reduction in daily OCS dose \\
\hline $\begin{array}{l}\text { NCT03688074 } \\
\text { (CASCADE) }\end{array}$ & $2018-2020$ & $\begin{array}{l}116 \text { adults with inadequately controlled } \\
\text { moderate-to-severe asthma, taking ICS and at } \\
\text { least one additional asthma controller }\end{array}$ & 2 & $\begin{array}{l}\text { Number of airway submucosal } \\
\text { inflammatory cells } / \mathrm{mm}^{2} \text { of } \\
\text { bronchoscopic biopsies }\end{array}$ \\
\hline $\begin{array}{l}\text { NCT03706079 } \\
\text { (DESTINATION) }\end{array}$ & 2019-2022 & $\begin{array}{l}966 \text { adults and adolescents with severe, } \\
\text { uncontrolled asthma }\end{array}$ & 3 & $\begin{array}{l}\text { Exposure-adjusted incidence of adverse } \\
\text { events and serious adverse events }\end{array}$ \\
\hline $\begin{array}{l}\text { NCT04048343 } \\
\text { (NOZOMI) }\end{array}$ & $2019-2021$ & $\begin{array}{l}66 \text { Japanese adults and adolescents with } \\
\text { inadequately controlled severe asthma }\end{array}$ & 3 & Rate of adverse events \\
\hline $\begin{array}{l}\text { NCT03927157 } \\
\text { (DIRECTION) }\end{array}$ & $2019-2023$ & $\begin{array}{l}396 \text { Chinese adults with severe, uncontrolled } \\
\text { asthma taking medium- to high-dose ICS and } \\
\text { at least one additional asthma controller with } \\
\text { or without OCS }\end{array}$ & 3 & Annualized asthma exacerbation rate \\
\hline
\end{tabular}

ICS Inhaled corticosteroids, LABA Long-acting $\beta_{2}$ agonist, OCS Oral corticosteroids, $P D_{15}$ Provoking dose to induce a $15 \%$ fall in forced expiratory volume in $1 \mathrm{~s}$, SC Subcutaneous

aims to evaluate the OCS-sparing potential of tezepelumab in adults with OCS-dependent asthma. Following OCS dose optimization, the 48-week treatment period comprises: a 4-week induction phase during which tezepelumab is introduced; a 36-week OCS reduction phase during which the OCS dose is tapered (dependent on the patient continuing to meet asthma control criteria); and an 8-week maintenance phase in which patients continue on their final OCS dose. The primary endpoint is the percentage reduction from baseline to week 48 in the prescribed daily OCS maintenance dose while not losing asthma control. DESTINATION (NCT03706079) [60] is a long-term extension of NAVIGATOR and SOURCE that addresses the safety and tolerability of tezepelumab for up to 2 years' treatment. In addition to these phase 3 studies, the phase 2 mechanistic study CASCADE (NCT03688074) [61] aims to evaluate the effect of tezepelumab on airway inflammation and airway remodelling in patients spanning the spectrum of $\mathrm{T} 2$ airway inflammation, as determined by epithelial molecular phenotyping. The primary endpoint is the change from baseline to week 28 in airway submucosal inflammatory cells (eosinophils, neutrophils, $\mathrm{T}$ cells and mast cells) from bronchoscopic biopsies. Secondary endpoints include assessments of reticular basement membrane thickening and airway epithelial integrity.

\section{Conclusions}

The disease burden of patients with severe asthma is considerable and has yet to be fully addressed with available treatment options, including biologic therapies. In particular, there are currently no approved therapies for patients with eosinophil-low asthma. Blocking the activity of TSLP has the potential to enact broader effects on airway inflammation than are achieved with current biologic therapies owing to its position at the top of the inflammatory cascade, from which it mediates a wide range of downstream processes that drive eosinophilic and neutrophilic inflammation, as well as structural changes to the airway. Clinical trials of TSLP blockade with tezepelumab completed to date have yielded promising results in patients with a variety of asthma phenotypes, who experienced significant reductions in exacerbation rates and improvements in lung function, symptom control and HRQoL. Studies in progress will provide further evidence of whether tezepelumab can be an effective treatment for a broad population of patients with severe asthma.

\section{Abbreviations}

FeNO: Fractional exhaled nitric oxide; GINA: Global Initiative for Asthma; HRQOL: Health-related quality of life; ICS: Inhaled corticosteroids; Ig: Immunoglobulin; IL: Interleukin; ILC2: Group 2 innate lymphoid cell; LABA: Long-acting $\beta_{2}$ agonist; OCS: Oral corticosteroids; SABA: Short-acting $\beta_{2}$ agonist; T2: Type 2 ; TSLP: Thymic stromal lymphopoietin 


\section{Acknowledgements}

The authors thank Richard Claes, PhD, of PharmaGenesis London, London, UK, for providing medical writing support, which was funded by AstraZeneca and Amgen.

\section{Authors' contributions}

All authors contributed to drafting of the manuscript and critically reviewed each draft. All authors read and approved the final manuscript.

\section{Funding}

The authors received no remuneration for the authorship or publication of this article.

\section{Availability of data and materials Not applicable.}

Ethics approval and consent to participate Not applicable.

\section{Consent for publication}

Not applicable.

\section{Competing interests}

AMG has: attended advisory boards for AstraZeneca, GlaxoSmithKline, Novartis, Sanofi and Teva; received speaker fees from AstraZeneca, Novartis, Roche and Teva; participated in research with AstraZeneca, for which his institution has been remunerated; attended international conferences with Teva; and held consultancy agreements with AstraZeneca, Sanofi and Vectura. MEW is an employee of National Jewish Health and has received consulting fees from AstraZeneca, Equillium, Genentech, GlaxoSmithKline, Novartis, Regeneron, Restorbio, Sanofi and Teva. CEB has received grants and consultancy fees from AstraZeneca.

\section{Author details}

${ }^{1}$ Royal Brompton Hospital, Sydney Street, London SW3 6NP, UK. ${ }^{2}$ National Jewish Health, Denver, CO, USA. ${ }^{3}$ University of Leicester, Leicester, UK.

Received: 5 May 2020 Accepted: 9 September 2020

\section{Published online: 15 October 2020}

\section{References}

1. Global Asthma Network. Global Asthma Report 2018. Available from: https:// www.globalasthmareport.org/. Accessed 12 March 2020.

2. Chung KF, Wenzel SE, Brozek JL, Bush A, Castro M, Sterk PJ, et al. International ERS/ATS guidelines on definition, evaluation and treatment of severe asthma. Eur Respir J. 2014:43(2):343-73.

3. Backman H, Jansson SA, Stridsman C, Eriksson B, Hedman L, Eklund BM, et al. Severe asthma - A population study perspective. Clin Exp Allergy. 2019;49(6):819-28.

4. Chen S, Golam S, Myers J, Bly C, Smolen H, Xu X. Systematic literature review of the clinical, humanistic, and economic burden associated with asthma uncontrolled by GINA Steps 4 or 5 treatment. Curr Med Res Opin. 2018;34(12):2075-88

5. Chen H, Gould MK, Blanc PD, Miller DP, Kamath TV, Lee JH, et al. Asthma control, severity, and quality of life: quantifying the effect of uncontrolled disease. J Allergy Clin Immunol. 2007;120(2):396-402.

6. McDonald VM, Hiles SA, Jones KA, Clark VL, Yorke J. Health-related quality of life burden in severe asthma. Med J Aust. 2018;209(S2):S28-33.

7. Chastek B, Korrer S, Nagar SP, Albers F, Yancey S, Ortega H, et al. Economic burden of illness among patients with severe asthma in a managed care setting. J Manag Care Spec Pharm. 2016;22(7):848-61.

8. Zeiger RS, Schatz M, Dalal AA, Qian L, Chen W, Ngor EW, et al. Utilization and costs of severe uncontrolled asthma in a managed-care setting. J Allergy Clin Immunol Pract. 2016;4(1):120-9.

9. Porsbjerg C, Menzies-Gow A. Co-morbidities in severe asthma: clinical impact and management. Respirology. 2017;22(4):651-61.

10. Bleecker ER, Menzies-Gow AN, Price DB, Bourdin A, Sweet S, Martin AL, et al. Systematic literature review of systemic corticosteroid use for asthma management. Am J Respir Crit Care Med. 2020;201(3):276-93.
11. Lefebvre P, Duh MS, Lafeuille MH, Gozalo L, Desai U, Robitaille MN, et al. Acute and chronic systemic corticosteroid-related complications in patients with severe asthma. J Allergy Clin Immunol. 2015;136(6):1488-95.

12. Carr TF, Zeki AA, Kraft M. Eosinophilic and noneosinophilic asthma. Am J Respir Crit Care Med. 2018;197(1):22-37.

13. Carr TF, Kraft M. Use of biomarkers to identify phenotypes and endotypes of severe asthma. Ann Allergy Asthma Immunol. 2018;121(4):414-20.

14. Moore WC, Hastie AT, Li X, Li H, Busse WW, Jarjour NN, et al. Sputum neutrophil counts are associated with more severe asthma phenotypes using cluster analysis. J Allergy Clin Immunol. 2014;133(6):1557-63.

15. Tliba O, Panettieri RA Jr. Paucigranulocytic asthma: uncoupling of airway obstruction from inflammation. J Allergy Clin Immunol. 2019;143(4):1287-94.

16. Cowan DC, Cowan JO, Palmay R, Williamson A, Taylor DR. Effects of steroid therapy on inflammatory cell subtypes in asthma. Thorax. 2010;65(5):384-90.

17. Saglani S, Lloyd CM. Novel concepts in airway inflammation and remodelling in asthma. Eur Respir J. 2015;46(6):1796-804.

18. Global Initiative for Asthma. Global strategy for asthma management and prevention. Updated 2019. Available from https://ginasthma.org/ginareports/. Accessed 27 Jan 2020.

19. Holguin F, Cardet JC, Chung KF, Diver S, Ferreira DS, Fitzpatrick A, et al. Management of severe asthma: a European Respiratory Society/American Thoracic Society guideline. Eur Respir J. 2020;55(1):1900588.

20. Busse W, Corren J, Lanier BQ, McAlary M, Fowler-Taylor A, Cioppa GD, et al. Omalizumab, anti-IgE recombinant humanized monoclonal antibody, for the treatment of severe allergic asthma. J Allergy Clin Immunol. 2001;108(2): 184-90.

21. Pavord ID, Korn S, Howarth P, Bleecker ER, Buhl R, Keene ON, et al. Mepolizumab for severe eosinophilic asthma (DREAM): a multicentre, double-blind, placebo-controlled trial. Lancet. 2012;380(9842):651-9.

22. Castro M, Zangrilli J, Wechsler ME, Bateman ED, Brusselle GG, Bardin P, et al. Reslizumab for inadequately controlled asthma with elevated blood eosinophil counts: results from two multicentre, parallel, double-blind, randomised, placebo-controlled, phase 3 trials. Lancet Respir Med. 2015;3(5): $355-66$.

23. Bleecker ER, FitzGerald JM, Chanez P, Papi A, Weinstein SF, Barker P, et al. Efficacy and safety of benralizumab for patients with severe asthma uncontrolled with high-dosage inhaled corticosteroids and long-acting beta2-agonists (SIROCCO): a randomised, multicentre, placebo-controlled phase 3 trial. Lancet. 2016;388(10056):2115-27.

24. Castro M, Corren J, Pavord ID, Maspero J, Wenzel S, Rabe KF, et al. Dupilumab efficacy and safety in moderate-to-severe uncontrolled asthma. N Engl J Med. 2018;378(26):2486-96.

25. Normansell R, Walker S, Milan SJ, Walters EH, Nair P. Omalizumab for asthma in adults and children. Cochrane Database Syst Rev. 2014(1):CD003559.

26. Farne HA, Wilson A, Powell C, Bax L, Milan SJ. Anti-IL5 therapies for asthma. Cochrane Database Syst Rev. 2017;9:CD010834.

27. Zayed Y, Kheiri B, Banifadel M, Hicks M, Aburahma A, Hamid K, et al. Dupilumab safety and efficacy in uncontrolled asthma: a systematic review and meta-analysis of randomized clinical trials. J Asthma. 2019;56(10):111019.

28. Xiong XF, Zhu M, Wu HX, Fan LL, Cheng DY. Efficacy and safety of dupilumab for the treatment of uncontrolled asthma: a meta-analysis of randomized clinical trials. Respir Res. 2019;20(1):108.

29. Mitchell PD, O'Byrne PM. Epithelial-derived cytokines in asthma. Chest. 2017; 151(6):1338-44

30. Corren J, Ziegler SF. TSLP: from allergy to cancer. Nat Immunol. 2019;20(12):1603-9.

31. Ying S, O'Connor B, Ratoff J, Meng Q, Mallett K, Cousins D, et al. Thymic stromal lymphopoietin expression is increased in asthmatic airways and correlates with expression of Th2-attracting chemokines and disease severity. J Immunol. 2005;174(12):8183-90.

32. Ying $S, O^{\prime}$ Connor B, Ratoff J, Meng Q, Fang C, Cousins D, et al. Expression and cellular provenance of thymic stromal lymphopoietin and chemokines in patients with severe asthma and chronic obstructive pulmonary disease. J Immunol. 2008;181(4):2790-8.

33. Shikotra A, Choy DF, Ohri CM, Doran E, Butler C, Hargadon B, et al. Increased expression of immunoreactive thymic stromal lymphopoietin in patients with severe asthma. J Allergy Clin Immunol. 2012;129(1):104-11.

34. Bleck B, Kazeros A, Bakal K, Garcia-Medina L, Adams A, Liu M, et al. Coexpression of type 2 immune targets in sputum-derived epithelial and dendritic cells from asthmatic subjects. J Allergy Clin Immunol. 2015;136(3): 619-27 (e5) 
35. Bjerregaard A, Laing IA, Poulsen N, Backer V, Sverrild A, Fally M, et al. Characteristics associated with clinical severity and inflammatory phenotype of naturally occurring virus-induced exacerbations of asthma in adults. Respir Med. 2017;123:34-41.

36. Li Y, Wang W, LV Z, Li Y, Chen Y, Huang K, et al. Elevated expression of IL-33 and TSLP in the airways of human asthmatics in vivo: A potential biomarker of severe refractory disease. J Immunol. 2018;200(7):2253-62.

37. He JQ, Hallstrand TS, Knight D, Chan-Yeung M, Sandford A, Tripp B, et al. A thymic stromal lymphopoietin gene variant is associated with asthma and airway hyperresponsiveness. J Allergy Clin Immunol. 2009;124(2):222-9.

38. Moffatt MF, Gut IG, Demenais F, Strachan DP, Bouzigon E, Heath S, et al. A large-scale, consortium-based genomewide association study of asthma. N Engl J Med. 2010;363(13):1211-21.

39. Torgerson DG, Ampleford EJ, Chiu GY, Gauderman WJ, Gignoux CR, Graves PE, et al. Meta-analysis of genome-wide association studies of asthma in ethnically diverse North American populations. Nat Genet. 2011;43(9):887-92.

40. Moorehead A, Hanna R, Heroux D, Neighbour H, Sandford A, Gauvreau GM, et al. A thymic stromal lymphopoietin polymorphism may provide protection from asthma by altering gene expression. Clin Exp Allergy. 2020; 50(4):471-8

41. Gauvreau GM, Sehmi R, Ambrose CS, Griffiths JM. Thymic stromal lymphopoietin: its role and potential as a therapeutic target in asthma. Expert Opin Ther Targets. 2020:1-16. https://pubmed.ncbi.nlm.nih.gov/3256 7399/.

42. Watson B, Gauvreau GM. Thymic stromal lymphopoietin: a central regulator of allergic asthma. Expert Opin Ther Targets. 2014;18(7):771-85.

43. Zhang $Y$, Zhou B. Functions of thymic stromal lymphopoietin in immunity and disease. Immunol Res. 2012;52(3):211-23.

44. Klose CS, Artis D. Innate lymphoid cells as regulators of immunity, inflammation and tissue homeostasis. Nat Immunol. 2016;17(7):765-74.

45. Tanaka J, Watanabe N, Kido M, Saga K, Akamatsu T, Nishio A, et al. Human TSLP and TLR3 ligands promote differentiation of Th17 cells with a central memory phenotype under Th2-polarizing conditions. Clin Exp Allergy. 2009;39(1):89-100.

46. Gao H, Ying S, Dai Y. Pathological roles of neutrophil-mediated inflammation in asthma and its potential for therapy as a target. J Immunol Res. 2017;2017:3743048.

47. Redhu NS, Shan L, Movassagh H, Gounni AS. Thymic stromal lymphopoietin induces migration in human airway smooth muscle cells. Sci Rep. 2013;3: 2301.

48. Kaur D, Doe C, Woodman L, Heidi Wan WY, Sutcliffe A, Hollins F, et al. Mast cell-airway smooth muscle crosstalk: the role of thymic stromal lymphopoietin. Chest. 2012;142(1):76-85.

49. Cao L, Liu F, Liu Y, Liu T, Wu J, Zhao J, et al. TSLP promotes asthmatic airway remodeling via p38-STAT3 signaling pathway in human lung fibroblast. Exp Lung Res. 2018;44(6):288-301.

50. Wu J, Liu F, Zhao J, Wei Y, Lv J, Dong F, et al. Thymic stromal lymphopoietin promotes asthmatic airway remodelling in human lung fibroblast cells through STAT3 signalling pathway. Cell Biochem Funct. 2013; 31(6):496-503.

51. Gauvreau GM, O'Byrne PM, Boulet LP, Wang Y, Cockcroft D, Bigler J, et al. Effects of an anti-TSLP antibody on allergen-induced asthmatic responses. N Engl J Med. 2014;370(22):2102-10

52. Corren J, Parnes JR, Wang L, Mo M, Roseti SL, Griffiths JM, et al. Tezepelumab in adults with uncontrolled asthma. N Engl J Med. 2017 377(10):936-46.

53. Sakamoto K, Matsuki S, Irie S, Uchida N, Hayashi N, Horiuchi M, et al. A phase 1, randomized, placebo-controlled study to evaluate the safety, tolerability, pharmacokinetics, and immunogenicity of subcutaneous tezepelumab in healthy Japanese men. Clin Pharmacol Drug Dev. 2020. https://doi.org/10.1002/cpdd.775.

54. Corren J, Garcia Gil E, Parnes J, Pham T, Griffiths J. Tezepelumab treatment effect on annualized rate of exacerbations by baseline biomarkers in uncontrolled severe asthma patients: phase 2b PATHWAY study. Am J Respir Crit Care Med. 2019;199:A2621.

55. Pham T-H, Ren P, Parnes JR, Griffiths JM. Tezepelumab reduces multiple key inflammatory biomarkers in patients with severe, uncontrolled asthma in the phase 2b PATHWAY study. Am J Respir Crit Care Med. 2019;199:A2677.

56. Upham JW, Jurak LM. How do biologicals and other novel therapies effect clinically used biomarkers in severe asthma? Clin Exp Allergy. 2020;50(9): 994-1006.
57. AstraZeneca. Tezepelumab granted Breakthrough Therapy Designation by US FDA. Available from: https://www.astrazeneca.com/media-centre/pressreleases/2018/tezepelumab-granted-breakthrough-therapy-designation-byus-fda-07092018.html. Accessed 5 Mar 2020.

58. ClinicalTrials.gov. Study to evaluate tezepelumab in adults and adolescents with severe uncontrolled asthma (NAVIGATOR). Available from: https:// clinicaltrials.gov/ct2/show/NCT03347279. Accessed 5 Mar 2020.

59. ClinicalTrials.gov. Study to evaluate the efficacy and safety of tezepelumab in reducing oral corticosteroid use in adults with oral corticosteroid dependent asthma (SOURCE). Available from: https://clinicaltrials.gov/ct2/ show/NCT03406078. Accessed 5 Mar 2020.

60. ClinicalTrials.gov. Extension study to evaluate the safety and tolerability of tezepelumab in adults and adolescents with severe, uncontrolled asthma (DESTINATION). Available from: https://clinicaltrials.gov/ct2/show/NCT03706 079. Accessed 5 Mar 2020

61. ClinicalTrials.gov. Study to evaluate tezepelumab on airway inflammation in adults with uncontrolled asthma (CASCADE). Available from: https:// clinicaltrials.gov/ct2/show/NCT03688074. Accessed 5 Mar 2020.

\section{Publisher's Note}

Springer Nature remains neutral with regard to jurisdictional claims in published maps and institutional affiliations.
Ready to submit your research? Choose BMC and benefit from:

- fast, convenient online submission

- thorough peer review by experienced researchers in your field

- rapid publication on acceptance

- support for research data, including large and complex data types

- gold Open Access which fosters wider collaboration and increased citations

- maximum visibility for your research: over $100 \mathrm{M}$ website views per year

At $\mathrm{BMC}$, research is always in progress.

Learn more biomedcentral.com/submissions 